\title{
An $\mathrm{SF}_{6}$ Tracer Study of the Flow Dynamics in the Stockton Deep Water Ship Channel: Implications for Dissolved Oxygen Dynamics
}

\author{
Paul J. Schmieder • David T. Ho • Peter Schlosser • \\ Jordan F. Clark • S. Geoffrey Schladow
}

Received: 23 February 2008/Revised: 22 August 2008 /Accepted: 29 August 2008 / Published online: 23 September 2008

(C) Coastal and Estuarine Research Federation 2008

\begin{abstract}
A sulfur hexafluoride $\left(\mathrm{SF}_{6}\right)$ tracer release experiment was conducted in the Stockton Deep Water Ship Channel (DWSC) to quantify mixing and transport rates. $\mathrm{SF}_{6}$ was injected in the San Joaquin River upstream of the DWSC and mapped for 8 days. From the temporal change in $\mathrm{SF}_{6}$ distributions, the longitudinal dispersion coefficient $\left(K_{x}\right)$ was determined to be $32.7 \pm 3.6 \mathrm{~m}^{2} \mathrm{~s}^{-1}$ and the net velocity was $1.75 \pm 0.03 \mathrm{~km}$ day ${ }^{-1}$. Based on the decrease in $\mathrm{SF}_{6}$ inventory during the experiment, the pulsed residence time for waters in the DWSC was estimated at $\sim 17$ days. Within
\end{abstract}

P. J. Schmieder • D. T. Ho $\cdot$ P. Schlosser

Lamont-Doherty Earth Observatory, Columbia University,

61 Route 9W,

Palisades, NY 10964, USA

P. J. Schmieder $(\bowtie) \cdot$ P. Schlosser

Department of Earth and Environmental Sciences,

Columbia University,

New York, NY 10027, USA

e-mail: schmied@ldeo.columbia.edu

D. T. Ho

Department of Oceanography, University of Hawaii,

Honolulu, HI 96822, USA

P. Schlosser

Department of Earth and Environmental Engineering,

Columbia University,

500 West 120th Street,

New York, NY 10027, USA

J. F. Clark

Department of Earth Science,

University of California at Santa Barbara,

Santa Barbara, CA 93106, USA

S. G. Schladow

Department of Civil and Environmental Engineering,

University of California at Davis,

Davis, CA 95616, USA the DWSC from Stockton downstream to Turner Cut, dissolved oxygen concentrations maintained a steady state value of $4 \mathrm{mg} \mathrm{l}^{-1}$. These values are below water quality objectives for the time of year. The low flow rates observed in the DWSC and the inability of oxygen-rich waters from downstream to mix into the DWSC upstream of Turner Cut contribute to the low dissolved oxygen concentration.

Keywords Dissolved oxygen.

Sacramento-San Joaquin delta .

Stockton deep water ship channel $\cdot \mathrm{SF}_{6} \cdot$ Tracer $\cdot$ Mixing

\section{Introduction}

The Stockton Deep Water Ship Channel (DWSC) is a segment of the lower San Joaquin River (SJR), located in the eastern portion of the Sacramento-San Joaquin River inland delta. The delta is comprised of a complex network of river channels and diversion canals. The natural river flows are altered by export pumping for industrial, agricultural, and drinking water demands. Waters from the SJR alone provide drinking water for 22 million California residents (Jassby and Van Nieuwenhuyse 2005). Flows are further altered within the delta by the use of temporary barriers and gates, which are used in part to protect endangered species and oppose the salt water intrusion upstream (Kimmerer 2002). For instance, a temporary barrier is installed at the junction of the SJR and Old River, $\sim 22 \mathrm{~km}$ upstream from the DWSC, twice a year. The timing of the installation is associated with spring and fall salmon runs and helps keep the salmon within the SJR. The fall installation also helps maintain higher water flows through the DWSC by reducing flows towards pumps in 
Old River. The higher flows aid in reducing the seasonal hypoxia that often develops this time of year.

Seasonal hypoxia is characteristic of many estuaries, including the DWSC portion of the SJR. The $11.5 \mathrm{~km}$ stretch of channel, from the confluence of the upstream SJR (USJR) with the DWSC in Stockton, CA, USA downstream to Turner Cut, routinely experiences low dissolved oxygen (DO) concentrations (Fig. 1). Although low DO concentrations can be observed for all months of the year, depressed values primarily occur between summer and fall (June to October). DO values typically range between $2-2.5 \mathrm{mg} \mathrm{l}^{-1}$ during this time period (Foe et al. 2002). Historically, the depressed DO values have existed within the DWSC since the 1960s (Bain and Pierce 1968; Lehman et al. 2004).

Low DO concentrations can have adverse impacts on aquatic life, including fish kills during times of severe hypoxia, fish egg and larvae mortality and growth rate reductions (Breitburg 2002). More directly, the SJR has traditionally served as a spawning ground for the endangered Chinook salmon. Low DO concentrations can prevent the upstream Fall migration of these fish which limits their ability to reach the spawning grounds (CRWQCB 2005). Consequently, the California Regional Water Quality Control Board (CRWQCB) has defined DO limits for the Sacramento-San Joaquin Delta. During the months of September through November, DO concentrations within the channel between the city of Stockton and downstream to Turner Cut must remain above $6 \mathrm{mg} \mathrm{l}^{-1}$. During all other times of the year, DO concentrations must remain above $5 \mathrm{mg} \mathrm{l}^{-1}$ (CRWQCB 2005). Violations of these regulations frequently occur. Over the span of the past three decades, the frequency of observing DO concentrations below $5 \mathrm{mg} \mathrm{l}^{-1}$ has not decreased (Lehman et al. 2004).

Many factors can contribute to low DO concentrations in estuary systems, but a few have been identified as most important for the DWSC. First, both point source and nonpoint source nutrient loading upstream of the DWSC contribute to increased algae growth, which subsequently is a source of oxygen demand for the DWSC. A very significant point source for nutrient loading is the Stockton Regional Wastewater Control Facility, which supplies a direct source of dissolved ammonia to the SJR system (Lehman et al. 2004). In natural unpolluted river systems, ammonia concentrations range between 0.005 and $0.04 \mathrm{mg} \mathrm{l}^{-1}$ (Meybeck 1993). The average ammonia concentration in the effluent discharge from the wastewater facility was 12.5 and $13.6 \mathrm{mg} \mathrm{l}^{-1}$ for the years 2000 and 2001, respectively, and the average ammonia concentration within the DWSC during the summer months in the years 2000 and 2001 was $0.40 \mathrm{mg}^{-1}$ with a maximum observed value of $1.10 \mathrm{mg} \mathrm{l}^{-1}$ (Lehman et al. 2004). Nitrate and phosphate also contribute significantly to the nutrient loading and furthermore contribute to significant

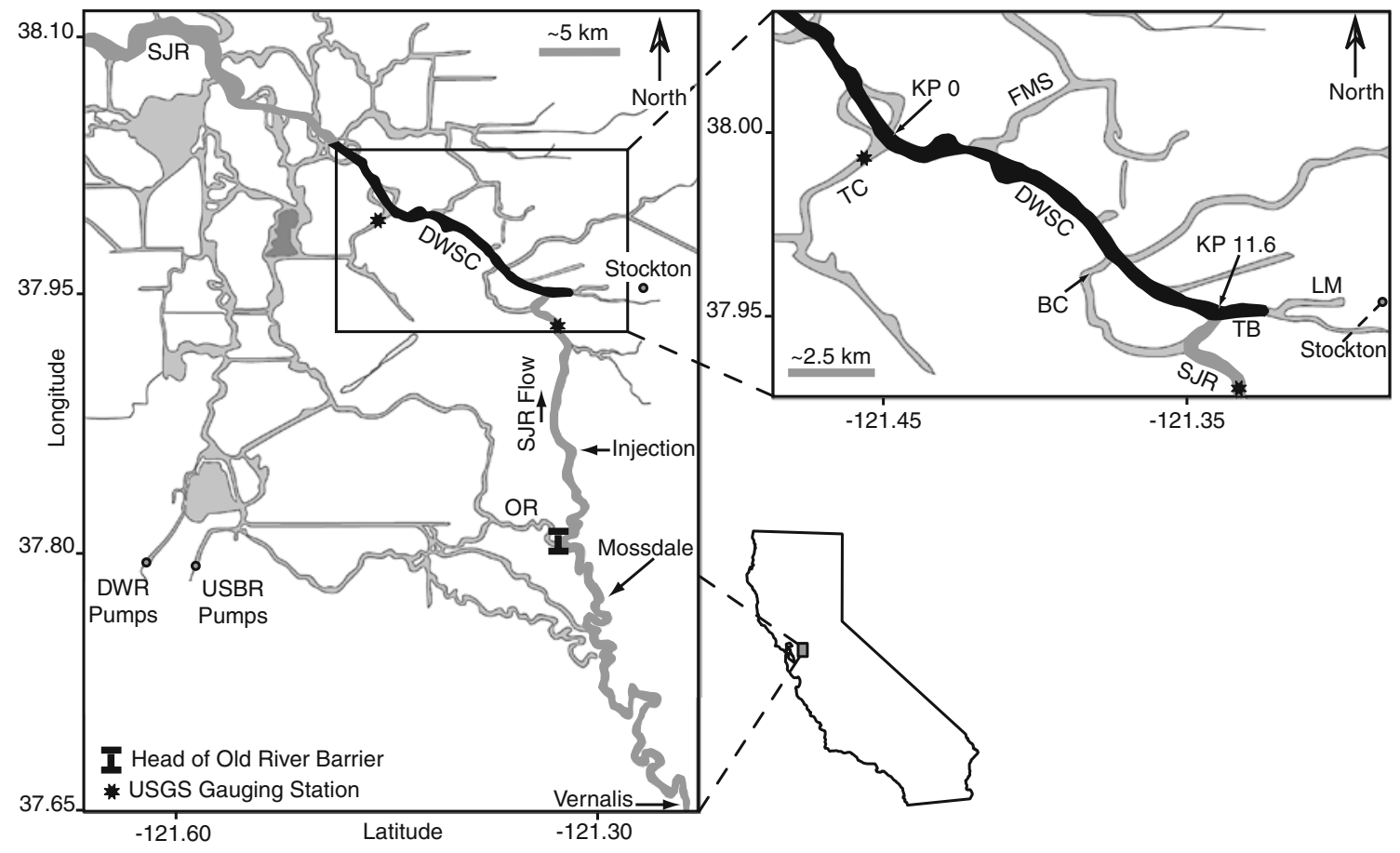

Fig. 1 Map depicting the study region within the Sacramento-San Joaquin Delta. The San Joaquin River (SJR) is shaded dark gray, the Deep Water Ship Channel (DWSC) portion of the SJR is highlighted in black, and the surrounding delta channels are shaded light gray. The locations along the DWSC are defined as the distance away from Turner Cut, with distance increasing upstream. The confluence of the
DWSC with the upstream SJR is $11.6 \mathrm{~km}$ upstream of Turner Cut. $B C$ Burns Cutoff at Rough and Ready Island, DWR Pumps Department of Water Resources pumping station, FMS Fourteen Mile Slough, KP kilometer point, $L M$ Lake McLeod, OR Old River, SJR San Joaquin River, $T B$ turning basin, TC Turner Cut, USBR Pumps United States Bureau of Reclamation pumping station 
algae growth (Diaz 2001). In natural river systems, nitrate concentrations range from 0.05 to $0.2 \mathrm{mg} \mathrm{l}^{-1}$, while phosphate concentrations range from 0.002 to $0.025 \mathrm{mg} \mathrm{l}^{-1}$ (Meybeck 1993). Nitrate concentrations in the SJR at Vernalis have ranged from 2.3 to $23.6 \mathrm{mg} \mathrm{l}^{-1}$ during the summer of 2001, and phosphate concentrations ranged from 0.063 to $0.104 \mathrm{mg} \mathrm{l}^{-1}$ during the same time period (Foe et al. 2002). For the years of 2000 and 2001, nitrification was identified as the largest contributor to oxygen demand (Lehman et al. 2004).

The second factor contributing to the low DO concentrations is the geometry of the DWSC. The DWSC is a dredged portion of the SJR, downstream of the city of Stockton. The increase in water depth moving from the USJR into the DWSC strengthens the influence of the biochemical oxygen demand (BOD) exerted on the system. The greater depth increases the time required to aerate the water column via gas exchange and increases the fraction of the water column removed from the photic zone, thereby increasing the portion of the water column that experiences net respiration. Finally, reduced net flows down the SJR during periods of the year increase the residence time of waters in the DWSC which consequently strengthens the influence of the BOD exerted on the system (CRWQCB 2005). Modeling results conducted for periods when the barrier at the head of Old River is in place and when there is no export pumping down Old River for agricultural and drinking water usage also suggest that substantial reductions in DO depletion can occur by maintaining flow down the SJR (Fig. 1; Jassby and Van Nieuwenhuyse 2005).

The goal of this study was to investigate the mixing dynamics in the DWSC portion of the SJR through the use of an sulfur hexafluoride $\left(\mathrm{SF}_{6}\right)$ tracer release experiment. This method allows the quantification of mixing and residence times (e.g., Clark et al. 1996; Ho et al. 2002), as well as the examination of the connectivity of the different hydrological components in the DWSC system by determining the net velocity, the dispersion coefficient, and gas exchange rates from changes in tracer distribution and concentrations with time. Knowledge of the connectivity, transport, and mixing rates will enhance our understanding of the development and persistence of the low DO zone within the DWSC.

\section{Study Location}

The SJR, at $530 \mathrm{~km}$ long, is the second largest river in California and drains an area of $19,153 \mathrm{~km}^{2}$. Its headwaters are in the Sierra Nevada Mountain Range, and the river passes through the dense agricultural region of the San Joaquin Valley. It ultimately flows west and combines with the Sacramento River to form the Sacramento-San Joaquin Delta (Kratzer et al. 2004), which drains into San Francisco Bay.
The DWSC (Fig. 1) is located $125 \mathrm{~km}$ due east of the Golden Gate Bridge, which is located at the entrance to San Francisco Bay. Dredging of the DWSC to a depth of $9.25 \mathrm{~m}$ commenced in the 1930s, and between 1984 and 1987, the channel was deepened to $10.75 \mathrm{~m}$ (Bowersox 2002). The SJR is tidally influenced up to Vernalis, CA, located $48 \mathrm{~km}$ upstream of the confluence between the USJR and the DWSC at the Port of Stockton. Upstream of the confluence in Stockton, the mean width of the SJR is $60 \mathrm{~m}$ and the mean depth is $\sim 3.3 \mathrm{~m}$ with a tidal range of $1.2 \mathrm{~m}$. The DWSC downstream of Stockton has tidal flows that range between 55 and $115 \mathrm{~m}^{3} \mathrm{~s}^{-1}$ and a tidal range of $1 \mathrm{~m}$. The mean annual rainfall recorded in Stockton for the past 49 years is $354 \mathrm{~mm}$ per year, of which $89 \%$ falls between November and April. The mean SJR discharge recorded at Vernalis peaks at $236 \mathrm{~m}^{3} \mathrm{~s}^{-1}$ at the beginning of June and rapidly decreases to a minimum of $40 \mathrm{~m}^{3} \mathrm{~s}^{-1}$ during the month of August. Typically, flows slowly increase from August to December but remain below $75 \mathrm{~m}^{3} \mathrm{~s}^{-1}$ during this period.

\section{Materials and Methods}

Past studies have successfully utilized $\mathrm{SF}_{6}$ as a tracer in both river and estuarine environments (e.g., Clark et al. 1996; Ho et al. 2002, 2006b; Caplow et al. 2003, 2004a, b). $\mathrm{SF}_{6}$ is primarily of anthropogenic origin, and its atmospheric mixing ratio has been increasing since the $1950 \mathrm{~s}$ (Maiss and Brenninkmeijer 1998). The primary use of $\mathrm{SF}_{6}$ is in high voltage switching gears as an electrical insulator. For tracer studies, $\mathrm{SF}_{6}$ is considered conservative when losses due to air-water gas exchange are accounted for in mass inventories. This loss can be quantified directly by injecting a second volatile tracer (e.g., ${ }^{3} \mathrm{He}$; Clark et al. 1994, 1996) or indirectly by using wind speed-based gas exchange parameterizations. $\mathrm{SF}_{6}$ also works well as a tracer for long-term (days to weeks) and large spatial scale (tens of kilometers) studies, whereas dyes like fluorescein are better suited for smaller time and length scales (Ho et al. 2006b).

For 9 days starting on August 14, 2005 (day 0), an $\mathrm{SF}_{6}$ tracer release experiment was conducted within the USJR and the DWSC portion of the SJR. On day 0, approximately $1.6 \mathrm{~mol}$ of $\mathrm{SF}_{6}$ were injected into the USJR over a period of $10 \mathrm{~min}$ at a mean depth of $3.3 \mathrm{~m}$, while the boat traversed the width of the river channel. The injection was located $13 \mathrm{~km}$ upstream of the confluence between the USJR and the DWSC and occurred at slack before ebb tide (SBE). Based on the decay of the total $\mathrm{SF}_{6}$ mass inventory between days 2 and $8, \sim 6.5 \times 10^{-2} \mathrm{~mol}^{\text {of } \mathrm{SF}_{6}}(\sim 4 \%$ of the amount released) actually dissolved during tracer injection. This value is significantly lower than those achieved in previous experiments (e.g., Ho et al. 2002; Caplow et al. 
2003) and is most likely due to the shallower depth of the tracer injection. As the gas was injected at shallower depths, the bubbles have less time to equilibrate with the surrounding water, and the decreased hydrostatic pressure reduces the equilibrium concentration.

$\mathrm{SF}_{6}$ samples were analyzed using an automated, highresolution, measurement system that continuously measured the $\mathrm{SF}_{6}$ concentration in the water at approximately 1-min intervals (Ho et al. 2002; Caplow et al. 2004a). This system included a membrane contactor (Liqui-Cel) to extract gases from the water sample, dual analytical columns to separate $\mathrm{SF}_{6}$ from other gases, and a gas chromatograph with an electron capture detector to measure $\mathrm{SF}_{6}$. For this experiment, modifications were made to the original system to use a peristaltic pump in place of the submersible pump for water sampling.

While sampling, the gas stripping efficiency of the membrane contactor decreased due to particles $(<40 \mu \mathrm{m})$ clogging the contactor pores, and water flow rates varied since the flow is controlled manually. Final data calibrations account for the variability of these parameters, and $\mathrm{SF}_{6}$ concentrations are expressed in femtomoles $\left(10^{-15}\right)$ per liter of water $\left(\mathrm{fmol} \mathrm{l}^{-1}\right)$.

Following the tracer release (days 1-8), two longitudinal surveys were conducted each day in the DWSC and the USJR to define the vertical and horizontal distribution of the tracer patch. Locations along the channel are defined as the distance from Turner Cut in kilometers, with positive kilometer point (KP) values being located upstream of Turner Cut. Surveys commenced and ended when background $\mathrm{SF}_{6}$ concentrations were observed. At the time of the study, the predicted background $\mathrm{SF}_{6}$ concentration was $1.5 \mathrm{fmol}^{-1}$ based on a northern hemisphere background atmospheric ratio of 5.9 parts per trillion (NOAA/CMDL 2007) and solubility equilibrium for the conditions in the DWSC. The average conditions observed during the survey include a water temperature of $24.7^{\circ} \mathrm{C}$ and a salinity of 0.263 , where salinity values have no units as defined by the use of the Practical Salinity Scale (Lewis 1980). For solubility calculations, the low salinity value is negligible. Background concentration values were determined from surveys conducted outside of the tracer patch. The mean background concentration was $4.8 \mathrm{fmol} \mathrm{l}^{-1}$, a value approximately three times greater than that calculated from northern hemisphere background values. This result is not surprising, as previous studies have observed elevated atmospheric $\mathrm{SF}_{6}$ mixing ratios near urban areas (Ho and Schlosser 2000). The $\mathrm{SF}_{6}$ concentrations in the tracer patch were typically two-three orders of magnitude greater than background values and masked any elevated background signature.

Past experiments utilizing $\mathrm{SF}_{6}$ as a tracer in tidally influenced rivers have performed a tidal correction on the locations of the $\mathrm{SF}_{6}$ measurements in order to yield a synoptic distribution of the data (Clark et al. 1996; Ho et al. 2002, 2006b). As the DWSC is closed at the far eastern end of the turning basin (TB) at Lake McLeod, a standing wave persists within the study region, and the traditional correction following Ho et al. (2002) cannot be applied (Bowersox 2002). The standing wave is a result of a reflection of the tidal wave that progresses upstream at the end of the channel at Lake McLeod. The longitudinal transects for depicting the evolution of the tracer for this study are plotted at the time of sample collection rather than the time of slack before ebb tide (Figs. 2 and 3).

During the replicate surveys on days 5,6 , and 8 , a conductivity-temperature-depth (CTD) sonde (Sea-Bird SBE 19plus SEACAT Profiler) was lowered every 1 to $2 \mathrm{~km}$ to establish the temperature, salinity, and DO concentration gradients with depth. On days 3, 5, 6 and 8 , in order to define the vertical $\mathrm{SF}_{6}$ concentration gradients, water samples from depth were pumped through the continuous system and analyzed aboard the boat. Discrete samples from depth were also collected, stored in evacuated glass containers (Vacutainers) and later analyzed in the laboratory at The University of California, Santa Barbara following the experiment using the procedure outlined by Clark et al. (2004). A total of three stations were sampled on these transects and samples were collected from three to five depths at each station. The calibrations for the continuous $\mathrm{SF}_{6}$ measurements and the Vacutainers are different, and the values are not directly comparable. The vertical $\mathrm{SF}_{6}$ profile data presented within depicts the ratio of surface to bottom concentrations and not the absolute concentration. The use of the ratio allows for a relative comparison between data collected in Vacutainers and the data collected via the continuous system.

$\mathrm{SF}_{6}$ mass inventories for each day were calculated from measured $\mathrm{SF}_{6}$ concentrations and channel volume. The $\mathrm{SF}_{6}$ mass inventory for days following the tracer injection was conducted to determine the mass of $\mathrm{SF}_{6}$ dissolved into the system upon injection and to determine the e-folding loss rate for tracer within the system. Volumes for the portions of the DWSC sampled during the study were determined using electronic NOAA navigational chart 18663 in ArcGIS. Depth measurements provided in the charts are sparse, and caution was used when interpolating depth measurement. As the volumes of side channels and embayments are much less than the volume of the main channel, they are excluded from the inventory calculations. Also, the measured vertical and horizontal $\mathrm{SF}_{6}$ gradients were generally small, so the concentration in the center of the channel was applied in all directions.

Since $\mathrm{SF}_{6}$ is a gas, air-water gas exchange must be included in the mass balance, utilizing the parameterization of gas exchange based on wind speed from (Ho et al. 2006a):

$k_{600}=(0.266 \pm 0.019) u_{10}^{2}$ 

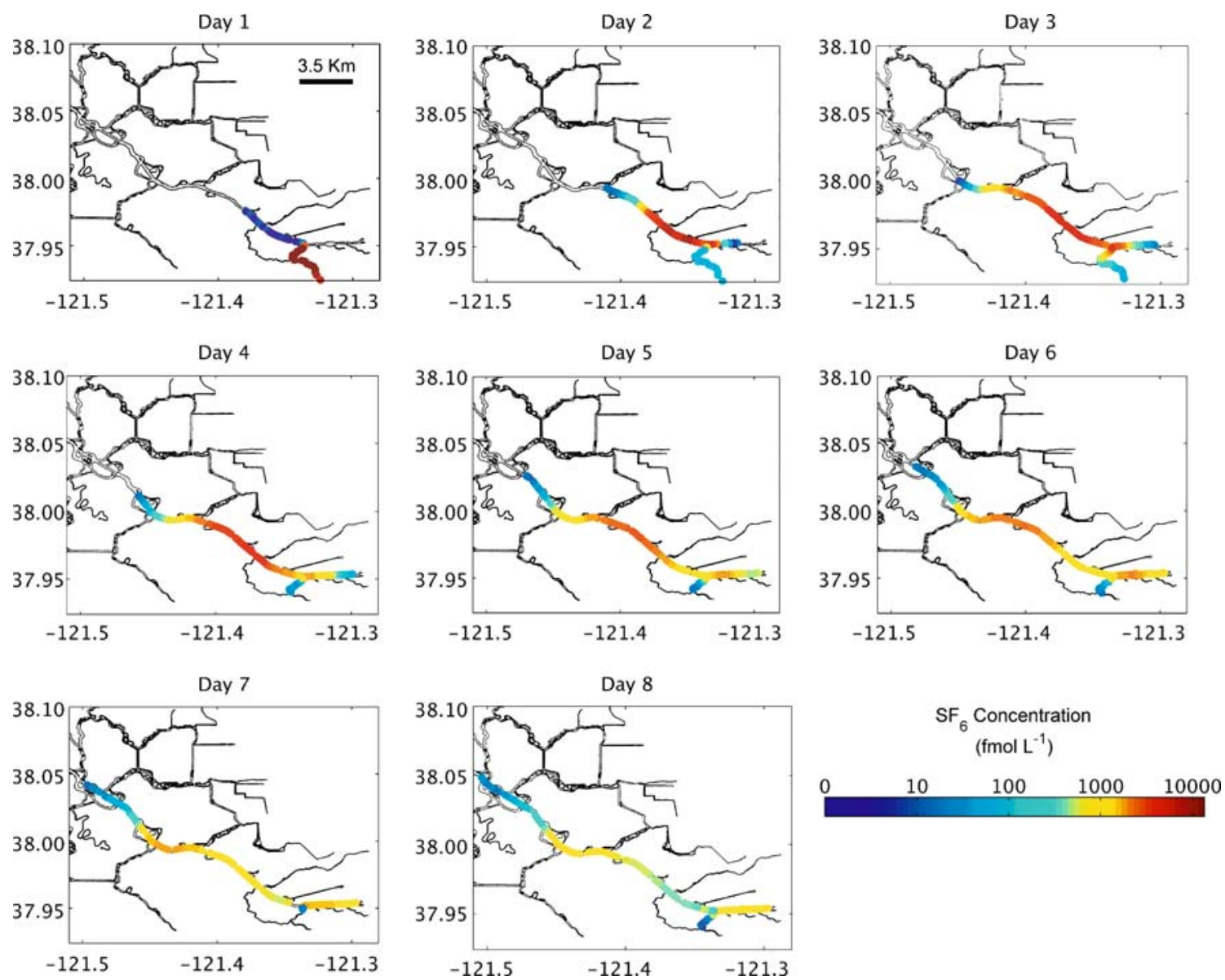

Fig. 2 Temporal evolution of the $\mathrm{SF}_{6}$ tracer patch from the SJR through the DWSC for eight consecutive daily surveys following the tracer release in the upstream $\mathrm{SJR} \mathrm{SF}_{6}$ concentrations are in units of fmol $\mathrm{l}^{-1}$

where $k_{600}\left(\mathrm{~cm} \mathrm{~h}^{-1}\right)$ is the gas transfer velocity normalized to a Schmidt number, Sc, of 600 , corresponding to $\mathrm{CO}_{2}$ in freshwater at $20^{\circ} \mathrm{C}$, a common reference condition $(\mathrm{Sc}=$ the kinematic viscosity of water divided by the molecular diffusivity of the gas in water). $u_{10}$ is the wind speed at $10 \mathrm{~m}$ height, and measurements were obtained from the National Weather Service Station located at the Stockton Municipal Airport, where the mean hourly $u_{10}$ wind speed was $3.6 \mathrm{~m} \mathrm{~s}^{-1}$ during the course of the study. Hourly $u_{10}$ values were applied to the wind speed parameterization and a daily average $k_{600}$ was determined. Because the wind speed parameterization is nonlinear, an enhancement correction $\left(\varepsilon=\overline{u_{10}^{2}} /{\overline{u_{10}}}^{2}\right)$ was made following the methods of Wanninkhof et al. (2004) and Ho et al. (2006a).

\section{Results}

Sulfur Hexafluoride

For 8 days following the tracer release, longitudinal transects were carried out in the DWSC and the USJR to define the evolution of the tracer. On day 1, the peak tracer concentration was located $11.5 \mathrm{~km}$ downstream of the tracer injection line and $1.5 \mathrm{~km}$ upstream of the confluence between the DWSC and the USJR. Small quantities of tracer entered the DWSC, and the maximum $\mathrm{SF}_{6}$ concentration detected on day 1 was 103,230 fmol $1^{-1}$. The distribution of $\mathrm{SF}_{6}$ concentrations was highly skewed upstream of the peak location, and tracer concentrations decreased rapidly to background values within $2 \mathrm{~km}$ downstream of the peak location (Fig. 2).

The transect performed on day 2 revealed that only small quantities of tracer remained within the USJR and that the majority of tracer mass had entered the TB and was being advected and dispersed downstream in the DWSC. At this time, the tracer patch had spread to a width of $8 \mathrm{~km}$ and was defined by multiple peaks in tracer concentration (Fig. 3). A peak concentration of 9,465 fmol $\mathrm{l}^{-1}$ was observed on day 2 . By day 3, the longitudinal tracer profile had grown to a width of $15 \mathrm{~km}$, and the peak tracer concentration had decreased by roughly one half to $5,002 \mathrm{fmol} \mathrm{l}^{-1}$. By the last day of surveys, day 8 , the tracer was detectable for nearly $23 \mathrm{~km}$, stretching from the eastern end of the TB downstream past Turner Cut and the peak concentration had decreased to $1,132 \mathrm{fmol}^{-1}$. 
Fig. 3 Temporal evolution of the longitudinal $\mathrm{SF}_{6}$ and dissolved oxygen profiles in the DWSC and the turning basin for days $2-8$ following the tracer injection. Locations upstream of the kilometer point 11.6 define the section of the channel leading to the TB and Lake McLeod, and Turner Cut is located at kilometer point 0 . Note that the concentration scale changes following day 2. $S B F$ slack before flood tide, $S B E$ slack before ebb tide
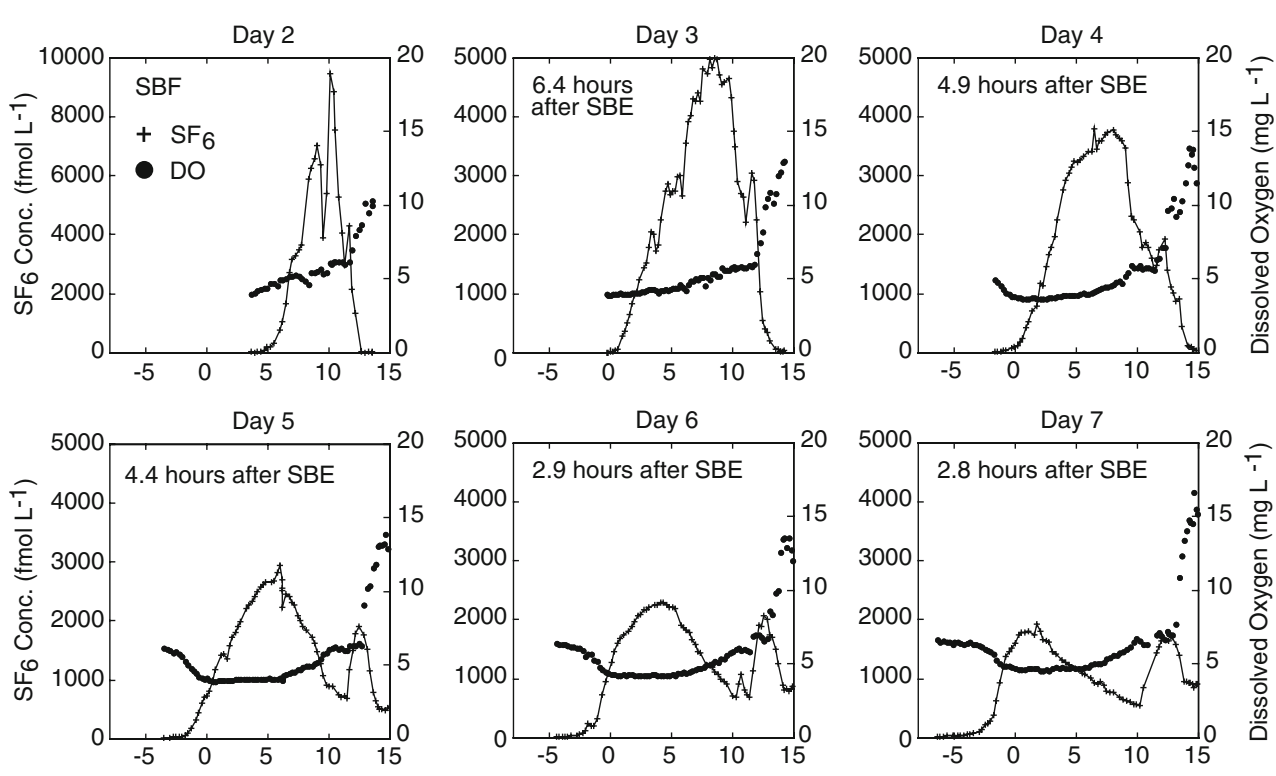

During the course of the repeated surveys, two distinct regions of high $\mathrm{SF}_{6}$ concentrations emerged. These two regions were separated at KP 11.6, which corresponds to the confluence between the DWSC and the USJR. The evolution of these water masses was noted from very early on in the surveys (day 2) and was very distinct by day 5 . The tracer peak along the DWSC stretch downstream of the confluence decayed more rapidly than the peak located within the $\mathrm{TB}$, with $\mathrm{SF}_{6}$ concentrations decreasing from $9,465 \mathrm{fmol} \mathrm{l}^{-1}$ on day 2 to $1,132 \mathrm{fmol}^{-1}$ on day 8 . For days 4 through 7 , peak concentrations in the TB remained relatively stable near 2,000 fmol $1^{-1}$. By day 8 , the $\mathrm{SF}_{6}$ concentrations were homogeneous in the TB with a concentration of $\sim 1,000 \mathrm{fmol}^{-1}$.

Starting on day 5 , when tracer tagged waters reached the confluence between Turner Cut and the DWSC (KP 0), tracer concentrations decreased rapidly. The furthest extent of tracer migration downstream of Turner Cut was $6 \mathrm{~km}$ on day 8. During this same time period, the portion of the $\mathrm{SF}_{6}$ profile between the peak location and the TB developed a very linear concentration gradient, thus skewing the profiles upstream. The minimum $\mathrm{SF}_{6}$ concentration at the confluence of the DWSC, USJR and the TB was relatively constant between days 5 and 8 at $700 \mathrm{fmol}^{-1}$.

\section{Dissolved Oxygen}

Along the length of the surveyed channel, the surface water ( $\sim 1 \mathrm{~m}$ in depth) DO concentrations were variable in space but temporally stable (Fig. 3). Upstream of the confluence between the DWSC and the USJR in the TB, DO concentrations in the upper $\sim 8 \mathrm{~m}$ of the water column remained above solubility equilibrium with the atmosphere for the duration of the study and reached values as high as $216 \%$ of solubility equilibrium $\left(19.7 \mathrm{mg} \mathrm{l}^{-1}\right)$ on day 8 . The values at a depth of $\sim 10 \mathrm{~m}$ ranged from $5.0-5.5 \mathrm{mg} \mathrm{l}^{-1}$ within the TB. The elevated oxygen values were attributed to the presence of visible algae blooms near the surface of the water. Downstream in the DWSC, surface DO concentrations repeatedly decreased from 6 to $\sim 4 \mathrm{mg} \mathrm{l}^{-1}$ over a distance of approximately $4 \mathrm{~km}$. Relatively constant surface DO concentrations of $4 \mathrm{mg} \mathrm{1^{-1 }}$ were observed for $7 \mathrm{~km}$ from KP 7 to KP 0 . The lowest DO concentration of $3.6 \mathrm{mg} \mathrm{l}^{-1}$ was observed on day 4 at KP 0.9 . Concentrations increased downstream of KP 0 , where surface DO values increased up to $6.5 \mathrm{mg} \mathrm{l}^{-1}$. The rise in DO values in this portion of the channel occurred over a shorter distance than the DO decrease that occurred upstream.

CTD profiles revealed that there exists little vertical stratification in DO except in the $\mathrm{TB}$ region where the 
highest DO concentrations were observed (Fig. 4). The DO signature of $\sim 7 \mathrm{mg} \mathrm{l}^{-1}$ from USJR water is clearly noted at depths below $6 \mathrm{~m}$ at KP 11.6 in the DWSC. The lowest surface DO concentrations were observed around Turner Cut and concentrations increased linearly moving downstream from KP -2 to end of the CTD profiles $(\mathrm{KP}-8)$.

\section{Salinity}

The salinity of the SJR has doubled during the past 60 years. The change in salinity is primarily attributed to upstream reservoir development, the use of higher salinity water for agriculture, and drainage from preexisting saline soils (CRWQCB 2004). Based on CTD profiles within the TB and the DWSC, the salinity structure from KP 13.2 downstream to KP -2.1 was fairly homogeneous with values ranging between 0.25 and 0.30 and averaging 0.28 (Fig. 4).

The USJR water imparted a characteristic salinity signal of 0.27 just downstream of KP 11.6. Upstream of this location in the TB, there was a slight increase in salinity that most likely developed from evaporation. Downstream in the DWSC, salinity concentrations were generally vertically homogeneous and tended to increase with distance downstream to Turner Cut. An exception to this trend occurred at KP 2.4. This location corresponds to the junction with Fourteen Mile Slough. The slight freshening documented at KP 2.4 could be attributed to this tributary, but no corresponding distinct signature was noticed in the
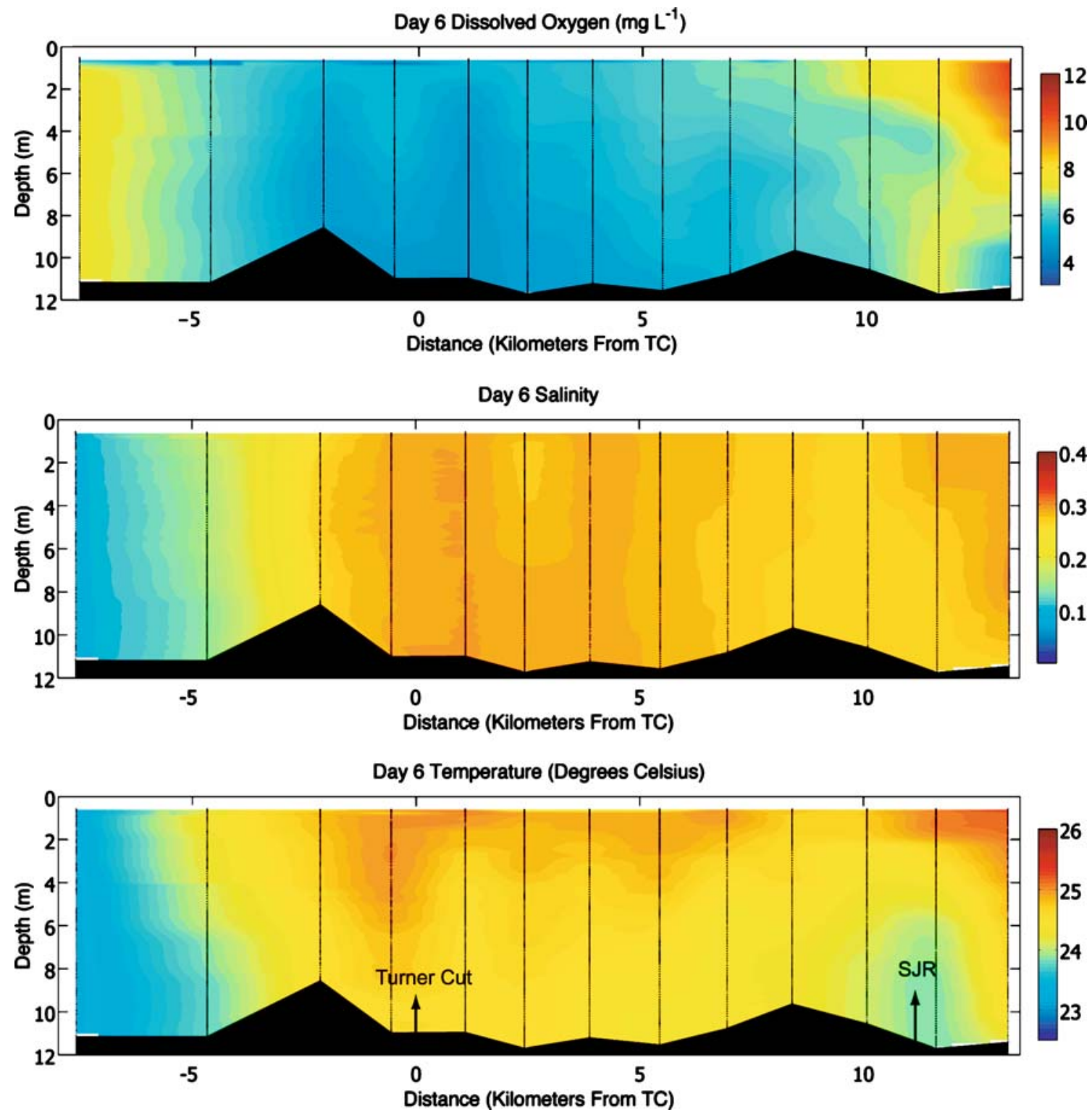

Fig. 4 Dissolved oxygen concentrations, salinity, and temperature measurements from CTD casts on day 6 of the longitudinal surveys. The survey commenced in the $\mathrm{TB}$ and progressed downstream to kilometer point -7.5 . The last CTD cast in the survey was conducted 30 min following slack before flood tide. The profiles conducted on this day of survey are representative of the study period 
DO and temperature profiles. Downstream of Turner Cut, waters freshened to 0.15 by $\mathrm{KP}-2.7$, and continued to freshen to 0.1 by KP -7.6 . The freshening downstream was associated with Sacramento River waters mixing upstream into the DWSC. In the vicinity of TC, significant mixing of Sacramento River waters and SJR waters has been documented (Brown 2002). Slight increases in surface salinity are most likely due to evaporation.

\section{Temperature}

Each water mass that composes the DWSC system displayed a characteristic signal in the temperature profile (Fig. 4). Slight thermal stratification was documented in the TB (KP 13.2) where surface water temperatures were $25.7^{\circ} \mathrm{C}$ and decreased to $24.1{ }^{\circ} \mathrm{C}$ near the channel bed. The USJR waters that flowed into the DWSC at KP 11.6 displayed a distinct temperature signal of $23.5^{\circ} \mathrm{C}$ from the channel bed up to $4 \mathrm{~m}$ depth. At this location, temperatures rose quickly up to $24.5^{\circ} \mathrm{C}$ for waters shallower than $4 \mathrm{~m}$. The cool water signal of the USJR had diminished by the time waters were advected to KP 4.5 downstream. Thermal stratification was slight but evident down to KP -2.1. It was here that the cooler signature of the Sacramento River water $\left(23.3^{\circ} \mathrm{C}\right)$ was imprinted onto the system.

\section{Discussion}

\section{San Joaquin River}

The hydrology of the DWSC and SJR system is highly dynamic. The system is best described by separating it into three components: (1) the USJR waters, (2) the TB, and (3) the DWSC section of the SJR down to Turner Cut. In the USJR, net velocities are greater in comparison to those in the DWSC due to a smaller cross-sectional area and, hence, faster net velocity for a given volumetric flow rate $(Q)$. Although advection should rapidly flush the USJR of all tracer tagged waters, tidal movement allows for exchange between the USJR and the DWSC sections. Each consecutive survey documented tracer tagged water within the USJR up to $2.2 \mathrm{~km}$ from the confluence. Provided that the peak concentration migrated $11.5 \mathrm{~km}$ from the injection line between the time of injection and the time of the first survey, the net velocity for the sampled portion of the USJR during the time of study was $13.2 \mathrm{~km} \mathrm{day}^{-1}$.

\section{Turning Basin}

From the longitudinal $\mathrm{SF}_{6}$ profiles in the DWSC and the TB beginning on day 2 , two peaks emerged on the upstream edge of the profile and persisted throughout the study. The peak furthest upstream corresponded to waters located within the TB. The existence of this peak was most likely derived by the tidal trapping mechanism characterized by Fisher et al. (1979). First, as water is advected out of the USJR, some tracer tagged waters may be entrained into the TB, while the majority flows downstream in the DWSC. As waters flow upstream during flood tide, tracer tagged water will enter both the TB and the USJR from the DWSC. Upon ebb tide, tracer-free water from the USJR separates the TB water from DWSC and two peaks are formed. It is possible that tidal waves in the DWSC and USJR are out of phase with the tidal wave in the TB embayment. Provided this is true, then the migration of tracer tagged waters from the TB will be separated from the bulk of the tracer mass since the currents within the TB and those in the DWSC will be out of phase.

Net velocity within the TB was very small, and dispersivity due to tidal motion determined the evolution of the tracer concentrations in the TB. By day 8, this tidal movement uniformly mixed the $\mathrm{SF}_{6}$ in the surface waters of the TB. Surveys on this day revealed that surface tracer concentrations were nearly homogenous from the confluence with the SJR up to Lake McLeod, which suggests that mixing processes acted on shorter timescales than the processes that created heterogeneity within the water mass. Within the TB though, the water column never fully mixes, and surface concentrations remain greater than at depth (Fig. 5).

The TB also influenced tracer concentrations downstream of KP 11.6. As the effluent from the USJR entered the DWSC, water from the $\mathrm{TB}$ was entrained and served as a continuous source of $\mathrm{SF}_{6}$ to the downstream system. This concept was supported by the fact that for days 6-8 (Fig. 3), there appeared to be mixing between two end members: mixing between the peak concentration in the DWSC and waters entering from the TB. The upstream limb of the $\mathrm{SF}_{6}$ tracer profile had a linear rather than the expected Gaussian shape, consistent with rapid mixing of waters from two end members. As the peak tracer concentrations within the TB decreased more slowly than the peak downstream, the efolding flushing time for waters in the TB appears to be longer than that for the downstream system.

\section{Deep Water Ship Channel}

From days $2-8$, the tracer mass advected in the DWSC in a fashion similar to that of standard tidal river systems. The net velocity of $1.75 \pm 0.03 \mathrm{~km} \mathrm{day}^{-1}$ was determined by plotting the location of the peak tracer concentration against the time since tracer injection and fitting a linear least-squares regression $\left(R^{2}=0.98\right.$; Fig. 6). A flushing time of $\sim 7$ days was then determined for the section of the channel from KP 11.6 downstream to KP 0 simply by length of the channel/ net velocity. This is a first order analysis of the hydraulic 


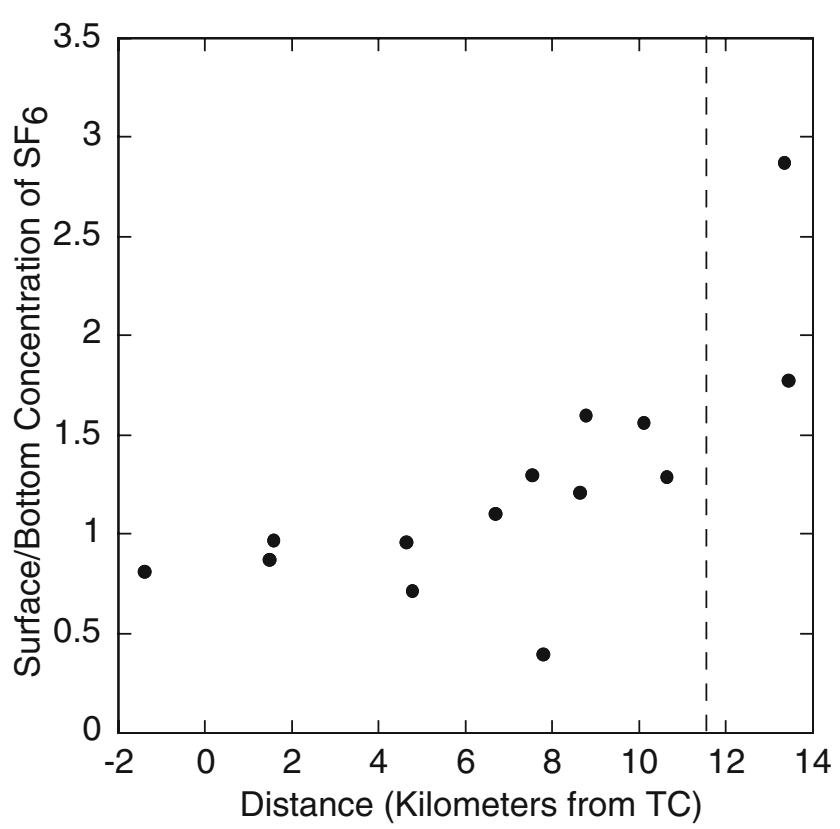

Fig. 5 Ratios of surface to bottom $\mathrm{SF}_{6}$ concentration compiled from all of the vertical concentration profiles. For locations upstream of KP 8 , waters are not vertically well mixed with respect to $\mathrm{SF}_{6}$ concentrations

timescales in the channel and assumes a constant crosssectional area. Also, given an average cross-sectional area of $1,500 \mathrm{~m}^{2}$ for the DWSC between KP 11.6 and KP 0 , the net volumetric flow rate was about $30.4 \mathrm{~m}^{3} \mathrm{~s}^{-1}$ through this section of the channel. The mean measured flow exiting the USJR for the duration of the study was $34.1 \mathrm{~m}^{3} \mathrm{~s}^{-1}$ (US Geological Survey (USGS) gauging station 11304810, below Garwood Bridge), which is in good agreement with the flow determined from the $\mathrm{SF}_{6}$ tracer release experiment.

Below KP 0, tracer concentrations eroded rapidly as a result of mixing with $\mathrm{SF}_{6}$-free Sacramento River waters from downstream, as well as loss of DWSC water into Turner Cut. Mixing with Sacramento River water has been documented at this location as well as the diversions down Turner Cut (Brown 2002). In this study, losses down Turner Cut are simply deduced from USGS gauging measurements, as sampling did not occur in the Turner Cut channel. Mean flows out of the DWSC into Turner Cut were $50.9 \mathrm{~m}^{3} \mathrm{~s}^{-1}$ during this study (USGS gauging station 11311300, Turner Cut Near Holt, CA). The increase in mean flow into Turner Cut above the measured SJR flow of $34.1 \mathrm{~m}^{3} \mathrm{~s}^{-1}$ is attributed to contributions from the Sacramento River downstream.

\section{Dispersion Coefficient}

To assess the dispersion in the system, we first use a simple one-dimensional (1-D) estimation. We assume that the transverse and the vertical are well mixed with regard to the $\mathrm{SF}_{6}$ tracer. The advection and the dispersion coefficient can be described by the 1-D advection diffusion equation (Fischer et al. 1979; Rutherford 1994):

$\frac{\partial c}{\partial t}+u \frac{\partial c}{\partial x}=K_{x} \frac{\partial^{2} c}{\partial x^{2}}-\lambda c$

where $c$ is averaged cross-sectional concentration, $t$ is time, $u$ is the net downstream velocity, $x$ is distance along the length of the channel, $K_{x}$ is the dispersion coefficient, and $\lambda$ is the first order loss rate for processes such as gas exchange.

In order to calculate the dispersion coefficient, we apply the change in moment method that tracks changes in the variance of a Gaussian curve fitted through the data, using the following equation (Fischer et al. 1979; Rutherford 1994):

$K_{x}=\frac{1}{2}\left(\frac{d \sigma_{x}^{2}}{d t}\right) \approx \frac{1}{2} \frac{\sigma_{x}^{2}\left(t_{2}\right)-\sigma_{x}^{2}\left(t_{1}\right)}{t_{2}-t_{1}}$

where $\sigma_{x}^{2}\left(t_{1}\right)$ and $\sigma_{x}^{2}\left(t_{2}\right)$ are the variance of the Gaussian curve fit for times 1 and 2, respectively. The times that are used in the calculation correspond to the time that the peak $\mathrm{SF}_{6}$ concentration was encountered during the daily surveys (Fig. 7). Only days 2-6 were used to determine the dispersion coefficient because the errors of the Gaussian fits were too large for days 7 and 8 . For these days, the longitudinal $\mathrm{SF}_{6}$ concentration profiles were highly skewed toward the upstream portion of the profile and were no longer Gaussian in shape. For the stretch of the DWSC from KP 11.6 to KP 0, the longitudinal dispersion coefficient was determined to be $32.7 \pm 3.6 \mathrm{~m}^{2} \mathrm{~s}^{-1}$, with an $R^{2}$ value for the fit of 0.89 (Fig. 8).

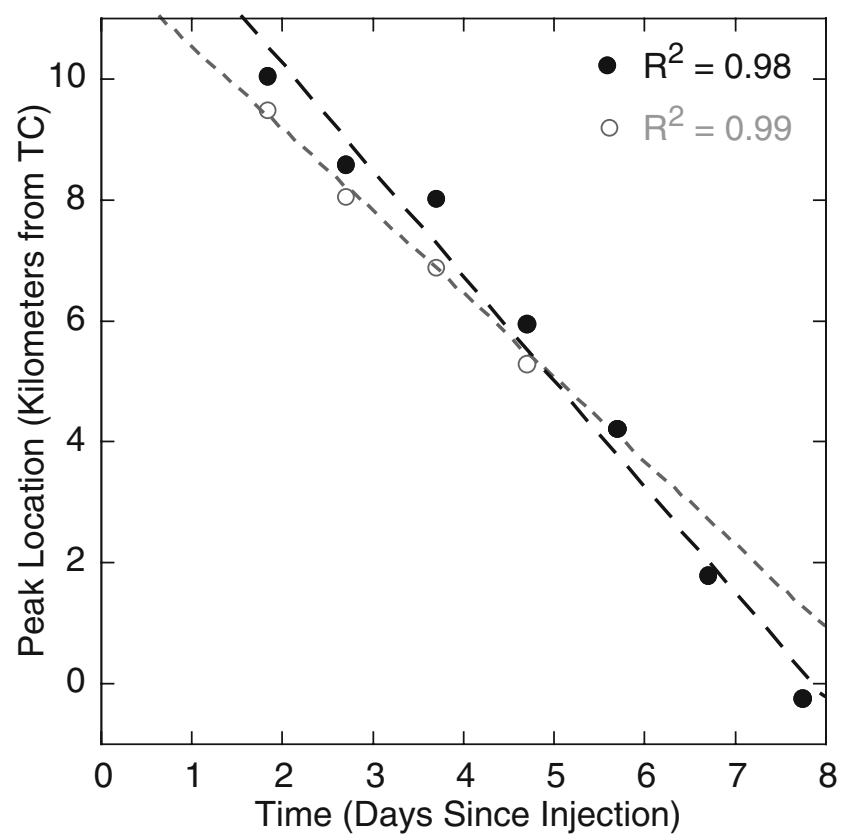

Fig. 6 Net velocity of the $\mathrm{SF}_{6}$ tagged water in the Stockton Deep Water Channel. The full dots represent the location of the measured $\mathrm{SF}_{6}$ maxima, and the open circles depict the location of the maxima of the fitted Gaussian distributions (Fig. 7). The net velocity of $1.75 \mathrm{~km}$ day $^{-1}$ is derived from location of the measured maxima 
Fig. 7 Gaussian distributions fitted to the observed longitudinal $\mathrm{SF}_{6}$ concentration profiles used to determine the dispersion within the DWSC for days 2-6
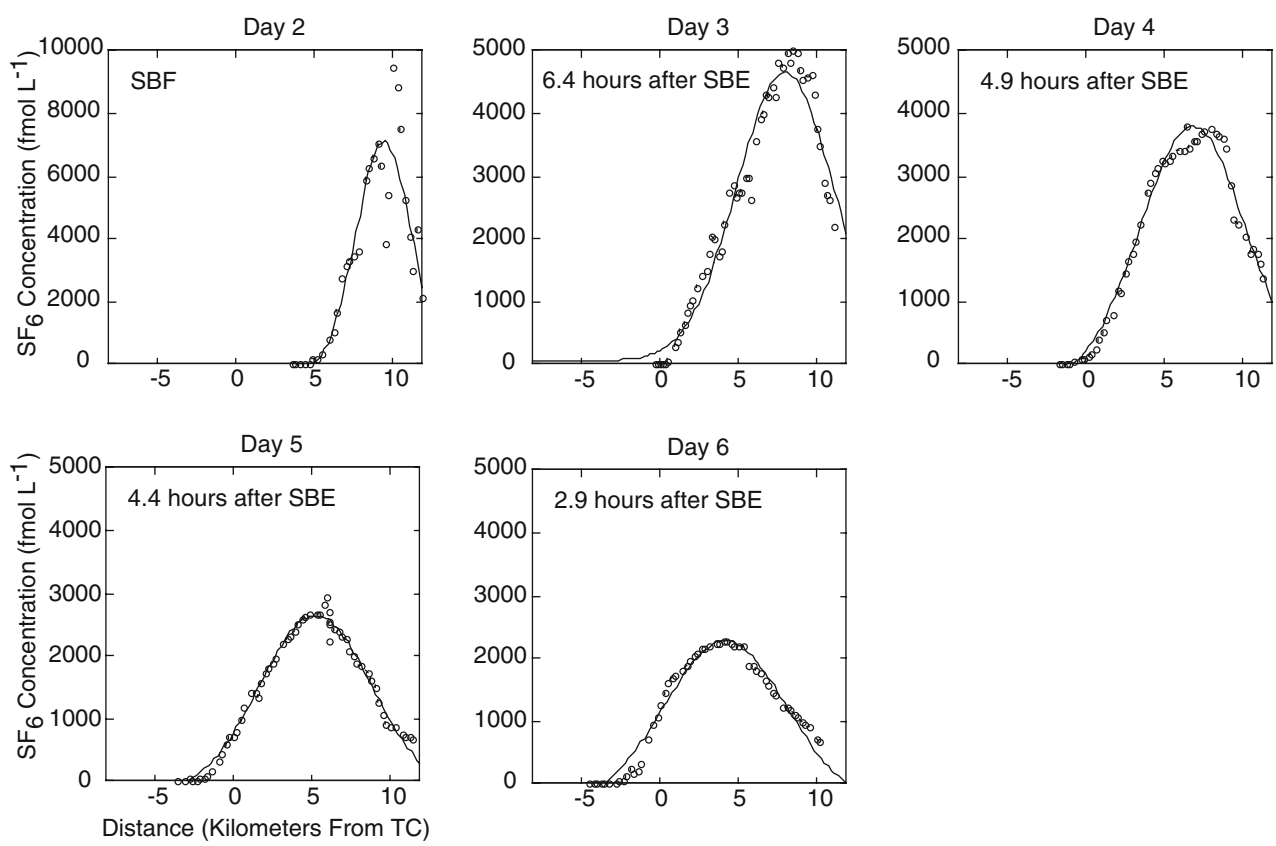

Downstream of this point, tracer tagged waters are diluted due to mixing with Sacramento River water and are removed from the DWSC via Turner Cut. Due to the complex nature of this process dispersion coefficients for this portion of the channel cannot be calculated using this method.

To better understand the relative importance of advection versus dispersion in the system, an estimate for the time scale of each process is computed. For advection within the DWSC

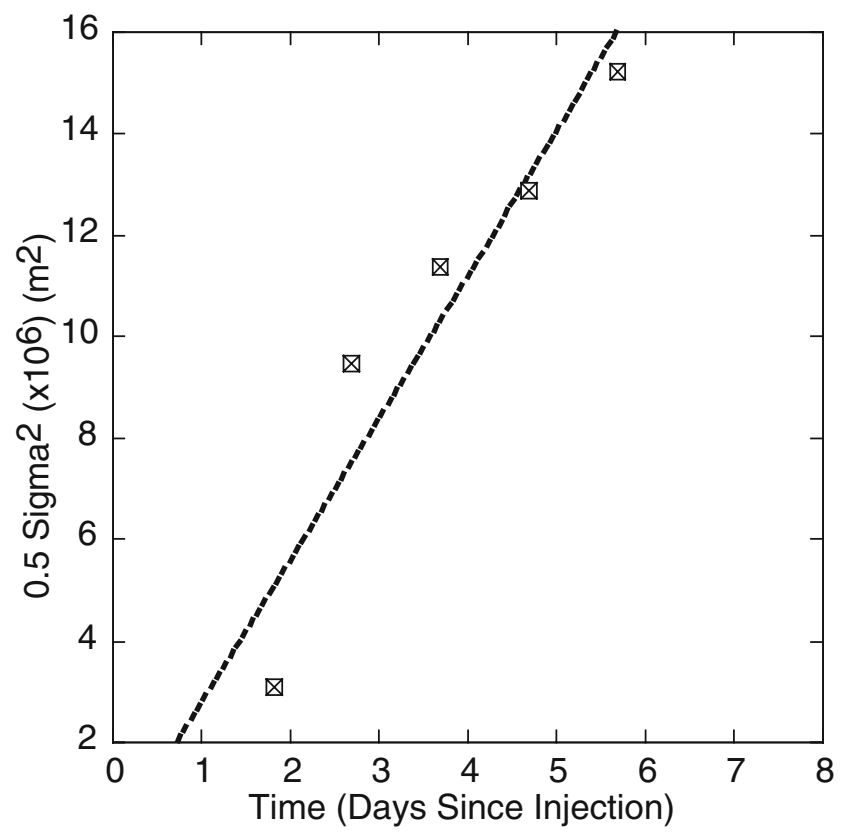

Fig. 8 Values of $1 / 2 \sigma^{2}$ used for the calculation of the dispersion coefficient plotted versus the time when the peak concentration was reached in the longitudinal surveys. The slope of the linear regression defines $K_{x}=32.7 \mathrm{~m}^{2} \mathrm{~s}^{-1}\left(R^{2}=0.89\right)$ down to Turner Cut, the time scale is defined as length/net velocity and yields an advective time scale of $\sim 7$ days. The dispersive time scale can be estimated by length ${ }^{2} / K_{x}$, and yields a timescale of $\sim 48$ days. Therefore, net advection should dominate as the removal mechanism for this stretch of the channel under the observed flow conditions.

\section{$\mathrm{SF}_{6}$ Mass Inventory}

The $\mathrm{SF}_{6}$ mass inventory was utilized to determine the pulse residence time (PRT) for waters within the DWSC and the TB (Miller and McPherson 1991; Sheldon and Alber 2002). This method is used to describe the time required to remove a portion of dissolved substance given that it was introduced to the system and one location as a pulse. Here, we present an e-folding PRT for waters in the DWSC, thus describing the time required to remove $63 \%$ of the tracer mass. The PRT is explicitly determined as $1 /$ loss rate. The $\mathrm{SF}_{6}$ mass inventory followed an exponential decay and yielded a first order loss rate $(\lambda)$ of 0.14 day $^{-1}\left(R^{2}=0.86\right)$ for combined flushing from the DWSC due to all loses such as advection, dispersion, and gas exchange (Fig. 9). This translated into a PRT of 7.1 days for the combined losses due to flushing from the system and gas exchange.

The decay in $\mathrm{SF}_{6}$ mass as predicted by gas exchange alone was also exponential. Application of the above gas exchange parameterization (Eq. 1) yielded a first order loss rate due to gas exchange $\left(\lambda_{\mathrm{GasEx}}=\right.$ re-aeration coefficient $)$ alone of 0.08 day $^{-1}\left(R^{2}=0.99\right)$. Therefore, the first order loss rate of tracer due to flushing or dilution out of the system was calculated as follows:

$\lambda_{\text {Flushing }}=\lambda-\lambda_{\mathrm{GasEx}}$ 


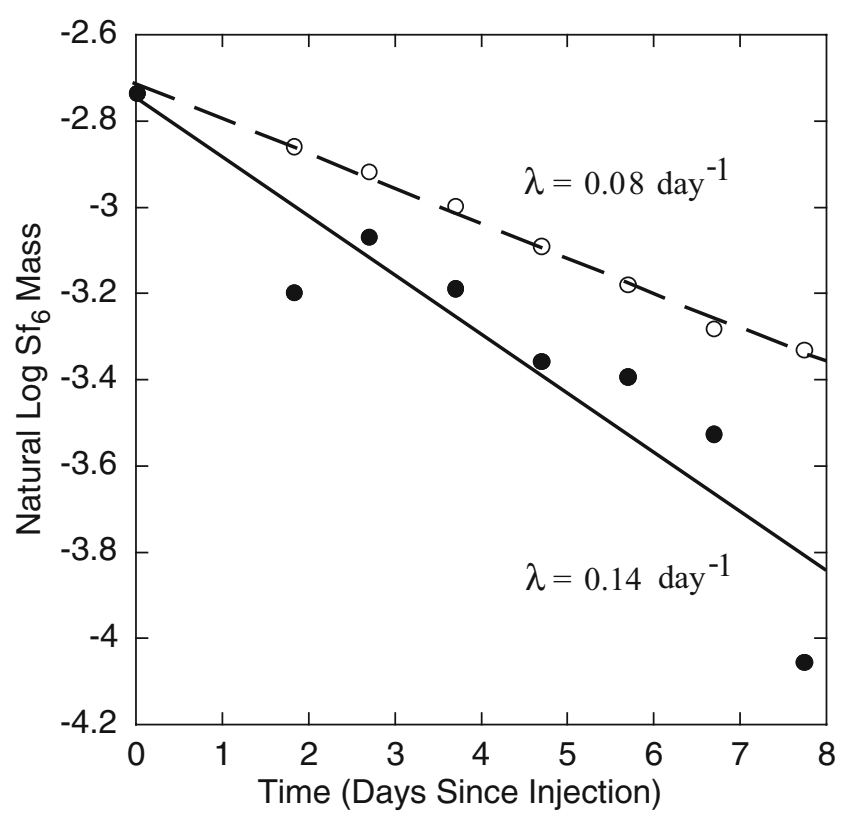

Fig. $9 \mathrm{SF}_{6}$ mass inventories based on loss due to predicted gas exchange alone (open grey circles) and the measured $\mathrm{SF}_{6}$ concentrations (closed black circles). The measured $\mathrm{SF}_{6}$ concentrations account for combined losses due to gas exchange and removal from the DWSC system via flushing

where $\lambda_{\text {Flushing }}=0.06$ day $^{-1}$, which translates to a PRT of 17 days if gas exchange was not included in the loss calculations. The 17-day PRT is much larger than the flushing time determined via the advection of the $\mathrm{SF}_{6}$ peak through the DWSC. This is attributed to the fact that the PRT derived from the mass inventory includes the tracer tagged waters in the TB, whereas the flushing time derived for the DWSC only includes waters downstream of the TB. On the last day of survey, the TB waters contained $26 \%$ of the tracer mass in the system.

For comparison, the air-water gas exchange versus wind speed parameterizations from Wanninkhof (1992), Clark et al. (1995), and Nightingale et al. (2000) were also applied to the data. Using these parameterizations, the first order loss rates due to gas exchange alone range from 0.076-0.12 day $^{-1}$, with the Nightingale parameterization yielding the lowest value and the Clark parameterization yielding the highest value. The variability of the determined loss rate due to gas exchange suggests that the PRT of 17 days for DWSC and TB portions of the system might serve as a lower bound under the observed flow conditions.

\section{Dissolved Oxygen}

During the course of the study, the longitudinal DO distributions remained more or less in steady state. This steady state was defined by DO concentrations of $\sim 6 \mathrm{mg} \mathrm{l}^{-1}$ at the confluence of the USJR and the DWSC, and a minimum DO concentration of $\sim 4 \mathrm{mg}^{-1}$ that was persistent from KP 7 to KP 0 .

There are four factors that determine the DO steady state balance within the DWSC system: (1) the biochemical oxygen demand and nitrogenous oxygen demand (NOD) contributed from upstream sources such as the Stockton Regional Wastewater Control Facility, agricultural runoff in the SJR watershed, and algal biomass; (2) the BOD from sediments along the length of the DWSC; (3) DO added by air-water oxygen exchange; and (4) water discharge rates through the system. The BOD and NOD added from upstream sources and from the sediments within the channel continually caused the DO to decrease moving downstream of the USJR to KP 7 in a nearly linear fashion. From this location downstream to KP 0 , the influence of the BOD exerted from the water column and the sediments must match the addition of DO from atmospheric gas exchange.

\section{Dissolved Oxygen Mass Balance}

Based on the net velocity in the DWSC calculated in this study, a first order mass balance was used to estimate the apparent biochemical oxygen demand $\left(\mathrm{BOD}_{A}\right)$ value for the DWSC during the study:

$$
\mathrm{BOD}_{A}=\text { DO Flux }_{\mathrm{SJR}}+\text { DO Flux }_{\mathrm{GasEx}}-\text { DO Flux }_{\mathrm{TC}}
$$

where $\mathrm{BOD}_{A}\left(\mathrm{~kg} \mathrm{day}^{-1}\right)$ is the rate of oxygen consumption through the combined oxidation processes in the sediments, as well as the organic and inorganic oxidation reactions within the water column; $\mathrm{DO}_{\mathrm{SJR}}\left(\mathrm{kg} \mathrm{day}^{-1}\right)$ is the $\mathrm{DO}$ flux associated with the supply of DO from the SJR to the DWSC; $\mathrm{DO}_{\mathrm{GaEEx}}\left(\mathrm{kg} \mathrm{day}^{-1}\right)$ is the DO flux added via airwater gas exchange and was derived from the $k_{600}$ value determined in this study; and $\mathrm{DO}_{\mathrm{TC}}$ is the $\mathrm{DO}$ flux associated with the removal of waters from the system via exports to Turner Cut and the downstream SJR. The difference in DO fluxes from inputs and removals is attributed to $\mathrm{BOD}_{A}$.

To calculate the oxygen flux from the SJR, the average observed surface DO concentration at the junction of the SJR and the DWSC, $7.1 \mathrm{mg}^{-1}$, was multiplied by an average SJR discharge rate of $35.3 \mathrm{~m}^{3} \mathrm{~s}^{-1}$, yielding a dissolved oxygen flux of $2.16 \times 10^{4} \mathrm{~kg} \mathrm{day}^{-1}$. The discharge rate includes additions of treated sewage effluent from the municipal sewage facility of $\sim 1.2 \mathrm{~m}^{3} \mathrm{~s}^{-1}$. The net oxygen flux into the channel due to predicted air-water gas exchange was calculated to be approximately $1.25 \times$ $10^{4} \mathrm{~kg} \mathrm{day}^{-1}$. For the oxygen exports at Turner Cut, we used the same flow rate as the input multiplied with a DO value of $4.0 \mathrm{mg} \mathrm{l}^{-1}$, yielding a value of $1.22 \times 10^{4} \mathrm{~kg} \mathrm{day}^{-1}$. To close the mass balance, any oxygen load deficit was attributed to BOD exerted on the system. Therefore, the $\mathrm{BOD}_{A}$ estimate was determined to be $2.19 \times 10^{4} \mathrm{~kg}_{\text {day }}{ }^{-1}$. 
The first order estimate for $\mathrm{BOD}_{A}$ loading rates compares well with the $\mathrm{BOD}_{10}$ loading rates presented by Volkmar and Dahlgren (2006), which were calculated under flow conditions $\left(32 \mathrm{~m}^{3} \mathrm{~s}^{-1}\right)$ very similar to this study. That study presented a loading rate of $\sim 2.7 \times 10^{4} \mathrm{~kg} \mathrm{day}^{-1}$ for samples collected in the SJR at Mossdale, $26 \mathrm{~km}$ upstream of the DWSC. One factor that contributes to this study's lower value is that dispersive fluxes are not included in the mass balance. As net advection appears to dominate over dispersion under the observed flows, only advective fluxes were included in the mass balance. The $\mathrm{BOD}_{A}$ loading rate is associated solely with the flushing time scale of 7 days calculated from the net velocity of the peak tracer concentration. A more complete mass balance based on a PRT of 17 days, which incorporates the effects dispersion, would increase the estimated $\mathrm{BOD}_{A}$ loading rate.

The 17-day PRT determined from the exponential decay of the $\mathrm{SF}_{6}$ mass inventory is comparable to flushing rates presented in other studies. Monsen et al. (2007) performed a modeling investigation to determine the impact of flow diversions on water quality and flushing times within the Sacramento-San Joaquin delta. The modeled flushing time for the DWSC was determined by counting the number of neutrally buoyant particles that remain in the DWSC domain over time, after being released evenly throughout the domain. The PRT calculation in this study is determined very similarly, except the initial release of particles is a pulse at one location and not spread evenly through the domain. For net flows slightly higher $\left(40-60 \mathrm{~m}^{3} \mathrm{~s}^{-1}\right)$ than observed in this study, the model flushing time was 16 days. For net flows near $0 \mathrm{~m}^{3} \mathrm{~s}^{-1}$, the flushing time increased to 31 days. The Monsen et al. (2007) modeling results indicate that DO depletions in the DWSC develop on flushing time scales of one to several weeks and also find that these results agree well with the BOD half-life of 12-15 days determined by Volkmar and Dahlgren (2006), a time-scale that leads to depleted DO concentrations. At the beginning of this study, the low DO conditions were already established, as flow rates similar to those observed were already occurring for a month prior to the investigation. The results presented within suggest DO depletions persist over the determined flushing and residence times.

The DO concentrations observed over the majority of the DWSC during this study fall below the CRWQCB regulations for DO of $6 \mathrm{mg} \mathrm{l}^{-1}$. The CRWQCB identified nutrient and algal loading, geometry of the DWSC, and low volumetric flow rates as potential factors contributing to the low dissolved oxygen concentrations. Out of the factors that can contribute to BOD such as nitrification of ammonium, oxidation of dissolved organic carbon and nitrogen, and respiration of algal biomass, nitrification has been identified as the principle contributor to BOD for waters in the DWSC (Lehman et al. 2004). For waters upstream of Mossdale, algal biomass was the principle source of BOD in the SJR (Volkmar and Dahlgren 2006). One way to alleviate the observed DO deficit is to decrease algal loads delivered from the USJR waters to the DWSC by reducing nutrient concentrations, but the high nutrient concentrations in the SJR suggest that nutrient reductions may not work alone (Volkmar and Dahlgren 2006).

The impacts of geometry and flow on the low DO are inversely correlated, as the net velocity decreases when the channel area increases stepping from the USJR into the DWSC. Modifications to the shipping channel geometry as a solution to DO depletions are highly unlikely, since shipping traffic will continue through the DWSC and water depths must be maintained.

For the duration of the tracer study and for the entire year of 2005, the water flow barrier at the head of Old River was removed. The Monsen et al. (2007) modeling results were for the same operational state of the barrier, and for comparison, with the barrier in place, model flushing times decreased by a factor greater than 5 . It has also been shown that on monthly time scales, net river flows provide the greatest impact on DO concentrations and exert more influence on changes in DO concentrations than ammonium and chlorophyll concentrations (Jassby and Van Nieuwenhuyse 2005). The Jassby and Van Nieuwenhuyse (2005) modeling results suggest that minor increases in net river flow can significantly decrease the DO deficit. The flow diverted down Old River was small in this study. By computing the difference in discharge rates at Vernalis, upstream of the SJR junction with Old River, and the Garwood Bridge gauging station, the flow diverted to Old River was only $6.7 \mathrm{~m}^{3} \mathrm{~s}^{-1}$. Depending on the level of export pumping down Old River, the entire SJR flow can be diverted down Old River thus reducing the net flow in the DWSC to zero and even reversing the direction of flow. This extreme case will certainly create a low DO problem and increase the flushing and residence times observed in this study.

\section{Conclusions}

The observed low DO concentrations suggest that the 17-day PRT determined for a net flow of $34.1 \mathrm{~m}^{3} \mathrm{~s}^{-1}$ is of a long enough timescale for DO depletions to persist and that the BOD within the DWSC has sufficient time to decrease oxygen concentrations. In order to comply with regulations, flushing and residence times would need to decrease so that the BOD from the SJR has less time to exert its full potential on the system. Shipping traffic through the DWSC will not be eliminated so modification to the channel geometry by reducing the volume of the channel is not a viable solution for decreasing the flushing and residence times in the DWSC. Reductions could partly be achieved by reducing water diversion and export flows from the 
USJR into Old River, so that net flows through the USJR into the DWSC increase. Reduced diversions at Turner Cut could also potentially allow more oxygen rich Sacramento River water to mix upstream into the DWSC. Most likely, a combination of reducing BOD sources and increasing flows down the USJR into the DWC is necessary to achieve the DO standards set by the CRWQCB.

Acknowledgements We thank J. McDermott and A. Sharma for their dedicated support in the field study, D. Hurst for lending us his miniature ECD, and L. Doyle for the post processing of the CTD profile data. Funding was provided by CALFED. This is LDEO contribution 7193.

\section{References}

Bain, R.C., and W.H. Pierce. 1968. San Joaquin estuary near Stockton, California: an analysis of the dissolved oxygen regimen. San Francisco, California: Department of the Interior, Federal Water Pollution Control Administration.

Bowersox, R.P. 2002. Design of a destratification system to control algae in a tidal channel. B.S. Thesis, University of California, Davis, California.

Breitburg, D. 2002. Effects of hypoxia, and the balance between hypoxia and enrichment, on coastal fishes and fisheries. Estuaries 25: 767-781.

Brown, R.T. 2002. Stockton deep water ship channel tidal hydraulics and downstream exchange. Available at: http://www.sjrtmdl.org/ technical/2001_studies/reports/final/brown_tidal2.htm. Part of Jones \& Stokes. Accessed 05 May 2007.

California Regional Water Quality Control Board, Central Valley Region. 2004. Amendments to the water quality control plan for the Sacramento River and San Joaquin River Basins for the control of salt and boron discharges into the lower San Joaquin River. Available at: http://www.waterboards.ca.gov/centralvalley/water issues/tmdl/central_valley_projects/vernalis_salt_boron/index.html. Accessed 03 May 2007.

California Regional Water Quality Control Board, Central Valley Region. 2005. Amendments to the water quality control plan for the Sacramento River and San Joaquin River Basins. Available at: $\mathrm{http}: / / w w w . w a t e r b o a r d s . c a . g o v / c e n t r a l v a l l e y / a v a i l a b l e \_d o c u m e n t s /$ basin_plans/SacSJR.pdf. Accessed 03 May 2007.

Caplow, T., P. Schlosser, D.T. Ho, and N. Santella. 2003. Transport dynamics in sheltered estuary and connecting tidal straits: $\mathrm{SF}_{6}$ tracer study in New York Harbor. Environmental Science \& Technology 37: 5116-5125. doi:10.1021/es034198+.

Caplow, T., P. Schlosser, D.T. Ho, and R.C. Enriquez. 2004a. Effect of tides on solute flushing from a strait: imaging flow and transport in the East River with $\mathrm{SF}_{6}$. Environmental Science \& Technology 38: 4562-4571. doi:10.1021/es035248d.

Caplow, T., P. Schlosser, and D.T. Ho. 2004b. Tracer study of mixing and transport in the upper Hudson River with multiple dams. Journal of Environmental Engineering-ASCE 130: 1498-1506. doi:10.1061/(ASCE)0733-9372(2004)130:12(1498).

Clark, J.F., R. Wanninkhof, P. Schlosser, and H.J. Simpson. 1994. Gas exchange rates in the tidal Hudson River using a dual tracer technique. Tellus 46B: 274-285.

Clark, J.F., P. Schlosser, R. Weppernig, M. Stute, R. Wanninkhof, and D.T. Ho. 1995. Relationship between gas transfer velocities and wind speeds in the tidal Hudson River determined by the dual tracer technique. In Air-water gas transfer, eds. Jähne, B. and E. Monahan. 783-800. Hanau, Germany: AEON.
Clark, J.F., P. Schlosser, M. Stute, and H.J. Simpson. 1996. $\mathrm{SF}_{6}{ }^{3} \mathrm{He}$ tracer release experiment: a new method of determining longitudinal dispersion coefficients in large rivers. Environmental Science and Technology 30: 1527-1532. doi:10. 1021/es9504606.

Clark, J.F., G.B. Hudson, M.L. Davisson, G. Woodside, and R. Herndon. 2004. Geochemical imaging of flow near an artificial recharge facility, Orange County, CA. Ground Water 42: 167-174. doi: 10.1111/j.1745-6584.2004.tb02665.x.

Diaz, R.J. 2001. Overview of hypoxia around the world. Journal of Environmental Quality 30: 275-281.

Fischer, H.B., E.J. List, R.C.Y. Koh, J. Imberger, and N.H. Brooks. 1979. Mixing in inland and coastal waters. New York: Academic.

Foe, C., M. Gowdy, and M. McCarthy. 2002. Draft Strawman allocation of responsibility. California Regional Water Quality Control Board Central Valley Region. http://www.sjrtmdl.org/ load_allocation/strawman.htm. Accessed 20 January 2007.

Ho, D.T., and P. Schlosser. 2000. Atmospheric $\mathrm{SF}_{6}$ near a large urban area. Geophysical Research Letters 2711: 1679-1682. doi:10.1029/1999GL006095.

Ho, D.T., P. Schlosser, and T. Caplow. 2002. Determination of longitudinal dispersion coefficient and net advection in the tidal Hudson River with a large-scale, high resolution $\mathrm{SF}_{6}$ tracer release experiment. Environmental Science \& Technology 36: 3234-3241. doi:10.1021/es015814+.

Ho, D.T., C.S. Law, M.J. Smith, P. Schlosser, M. Harvey, and P. Hill. 2006a. Measurements of air-sea gas exchange at high wind speeds in the Southern Ocean: implications for global parameterizations. Geophysical Research Letters 33: L16611. doi:10.1029/ 2006GL028295.

Ho, D.T., P. Schlosser, R.W. Houghton, and T. Caplow. 2006b. Comparison of $\mathrm{SF}_{6}$ and fluorescein as tracers for measuring transport processes in a large tidal river. Journal of Environmental Engineering-ASCE 132: 1664-1669. doi:10.1061/(ASCE) 0733-9372(2006)132:12(1664).

Jassby, A.D. and E.E. Van Nieuwenhuyse. 2005. Low dissolved oxygen in an estuarine channel (San Joaquin River, California): Mechanisms and models based on long-term time series. San Francisco Estuary \& Watershed Science 3(2): Article 2.

Kimmerer, W.J. 2002. Physical, biological, and management responses to variable freshwater flow in the San Francisco Estuary. Estuaries 256B: 1275-1290.

Kratzer, C.R., P.D. Dileanis, C. Zamora, S.R. Silva, C. Kendall, B.A. Bergamaschi, and R.A. Dahlgren. 2004. Sources and transport of nutrients, organic carbon, and Chlorophyll-a in the San Joaquin River upstream of Vernalis, California, during summer and fall, 2000 and 2001. United States Geological Survey, Water-Resources Investigations Report 03-4127. Sacramento, California.

Lehman, P.W., J. Sevier, J. Giulianotti, and M. Johnson. 2004. Sources of oxygen demand in the lower San Joaquin River, California. Estuaries 27: 405-418.

Lewis, E.L. 1980. The practical salinity scale 1978 and its antecedents. IEEE Journal of Oceanic Engineering OE-5: 3-8. doi:10.1109/JOE.1980.1145448.

Maiss, M., and C.A.M. Brenninkmeijer. 1998. Atmospheric $\mathrm{SF}_{6}$ : trends, sources, and prospects. Environmental Science and Technology 32: 3077-3086.

Meybeck, M. 1993. C, N, P and S in rivers: from sources to global inputs. In Interactions of $C, N, P$ and $S$ in biogeochemical cycles and global change, eds. R. Wollast, , F.T. Mackenzie, and L. Chou, 163-193. Berlin, Heidelberg, Germany: Springer.

Miller, R.L., and B.F. McPherson. 1991. Estimating estuarine flushing and residence times in Charlotte Harbor, Florida, via salt balance and a box model. Limnology and Oceanography 36: 602-612. 
Monsen, N.E., J.E. Cloren, and J.R. Burau. 2007. Effects of flow diversions on water and habitat quality: examples from California's highly manipulated Sacramento-San Joaquin Delta. San Francisco Estuary \& Watershed Science 5(3): Article 2.

National Oceanic and Atmospheric Administration-Climate Monitoring and Diagnostics Laboratory (NOAA/CMDL). 2007. Atmospheric sulfur hexafluoride concentrations. http://www.esrl.noaa. gov/gmd/. Accessed 15 March 2007.

Nightingale, P.D., P.S. Liss, and P. Schlosser. 2000. Measurements of air-sea gas transfer during an open ocean algal bloom. Geophysical Research Letters 27: 2117-2120. doi:10.1029/ 2000 GL011541.

Rutherford, J.C. 1994. River mixing. New York: Wiley.
Sheldon, J.E., and M. Alber. 2002. A comparison of residence time calculations using simple compartment models of the Altamaha River Estuary, Georgia. Estuaries 256B: 1304-1317.

Volkmar, E.C., and R.A. Dahlgren. 2006. Biological oxygen demand dynamics in the lower San Joaquin River, California. Environmental Science \& Technology 40: 5653-5660. doi:10.1021/ es0525399.

Wanninkhof, R. 1992. Relationship between wind speed and gas exchange over the ocean. Journal of Geophysical Research 97: 7373-7382. doi:10.1029/92JC00188.

Wanninkhof, R., K.F. Sullivan, and Z. Top. 2004. Air-sea gas transfer in the Southern Ocean. Journal of Geophysical Research 109: C08S19. doi:10.1029/2003JC001767. 